\title{
GCU
}

Glasgow Caledonian

University

University for the Common Good

\section{Effects of 17a-ethinyl estradiol exposure on estrogen receptors $a$ and $B$ and vitellogenins A, B and C mRNA expression in the liver of sand goby (Pomatoschistus minutus)}

Humble, Joseph; Saaristo, Minna; Lindstrom, Kai; Lehtonen, Kari; Craft, John

Published in:

Marine Environmental Research

DOI:

10.1016/j.marenvres.2014.01.006

Publication date:

2014

Document Version

Author accepted manuscript

Link to publication in ResearchOnline

Citation for published version (Harvard):

Humble, J, Saaristo, M, Lindstrom, K, Lehtonen, K \& Craft, J 2014, 'Effects of 17a-ethinyl estradiol exposure on estrogen receptors $a$ and $B$ and vitellogenins $A, B$ and $C$ mRNA expression in the liver of sand goby

(Pomatoschistus minutus)', Marine Environmental Research, vol. 96, pp. 12-18.

https://doi.org/10.1016/j.marenvres.2014.01.006

\section{General rights}

Copyright and moral rights for the publications made accessible in the public portal are retained by the authors and/or other copyright owners and it is a condition of accessing publications that users recognise and abide by the legal requirements associated with these rights.

Take down policy

If you believe that this document breaches copyright please view our takedown policy at https://edshare.gcu.ac.uk/id/eprint/5179 for details of how to contact us. 


\section{Effects of $17 \alpha$-ethinyl estradiol exposure on estrogen receptors $\alpha$ and $\beta$ and vitellogenins $A$, $B$ and $C$ mRNA expression in the liver of sand goby (Pomatoschistus minutus)}

Joseph L. Humble ${ }^{a,+}$, Minna Saaristo ${ }^{b, * *}$, Kai Lindström ${ }^{c}$, Kari K. Lehtonen ${ }^{d}$ and John A. Craft ${ }^{a,{ }^{*}}$

a School of Health and Life Sciences, Glasgow Caledonian University, Cowcaddens Road, Glasgow, G4 OBA, United Kingdom

b Department of Bio and Environmental Sciences, University of Helsinki, Finland

c Department of Environmental and Marine Biology, Åbo Akademi University, Finland

d Marine Research Centre, Finnish Environment Institute, P.O.B. 14000251 Helsinki, Finland

* corresponding author: John A Craft, +44 141331 3220, j.a.craft@gcu.ac.uk

+ Current Address: City University of Hong Kong, Tat Chee Avenue, Kowloon, Hong Kong, China

** Current address: School of Biological Sciences, Monash University, Clayton campus, 3800 Victoria, Australia 


\section{Abstract}

This study aims to characterize the estrogen receptor (er) in sand goby (Pomatoschistus minutus) and determine the temporal effects of 17a-ethinyl estradiol (EE2) on er $\alpha$ and vitellogenin (vtg) gene expression in males. Two partial cDNA sequences (er $\alpha$ and er $\beta 1$ ) are presented showing conserved structural features with ers of other species. Transcript levels for both ers were low in control fish but EE2 exposure (11 ng/L, for 29 days) increased both to a pattern similar to vitellogenic females. The relative expression of three $v \operatorname{tg}$ genes ( $v \operatorname{tga}, v \operatorname{tg} b$ and $v \operatorname{tg} c$ ) along with er $\alpha$ was determined in control and male fish exposed to EE2 (11 ng/L) at multiple time-points over 29 days. All four transcripts were significantly induced due to exposure and expression rose during the time course with distinct temporal patterns and vtga reached a substantially higher level at the end of the time course coinciding with rapid elevation in era expression.

\subsection{Introduction}

Estrogenic endocrine disruptors (EED) interact with the endocrine systems of animals by engaging with the estrogen signal transduction pathways, resulting in estrogenic toxicity with a myriad of detrimental and adverse effects (Hiramatsu et al., 2005). 17 $\alpha$-ethinyl estradiol (EE2) is a model EED and is found to contaminate European coastal waters with concentrations fluctuating as high as $125 \mathrm{ng} / \mathrm{L}$ (Pojana et al., 2004). The sand goby (Pomatoschistus minutus) is a small benthic fish that inhabits European coastal and estuarine environments. Sand goby have a one-year life cycle with distinctive well-characterized reproductive behaviours, for example sand goby males build nests into which females are lured to lay their eggs (Healey, 1971). In earlier works, sand goby has been utilized as a model in ecotoxicology for the study of endocrine disruption in both controlled exposure studies (Saaristo et al., 2009) and environmental monitoring (Kirby et al., 2003). Exposure of male and female animals to EE2 was shown to have adverse effects on reproductive output and mating behaviours (Robinson et al., 2003; Saaristo et al., 2010a, 2010b). The molecular mechanisms by which female egg production is impaired are poorly understood. In these studies it was difficult to contextualize the 
apical endpoints with the classic molecular biomarkers of estrogenic exposure, such as expression of vitellogenin (vtg), partially because at that time, only a small fragment a single vtg was available. Recently this situation has been improved when three vtgs transcripts were identified and shown to be inducible by EE2 exposure in male sand goby (Humble et al., 2013). The three vtg complete cDNA sequences have now been fully sequenced (accession AG064301.1 AG064302.1 and AG064303.1). Although male hepatic vtg is known to be inducible by exposure to EE2, the EED induced expression patterns of multiple vtg genes over time are unknown.

The er is central to the estrogen transduction pathway that is both crucial to vitellogenesis and EED mediated toxicity. Typically teleost fish have three subtypes of er (er $\alpha$, er $\beta 1$ and er $\beta 2)$ (Hawkins et al., 2000; Sabo-Attwood et al., 2004). era is known to be up-regulated by high level EED exposure in male fish (Katsiadaki et al., 2002) and erB1 is known to be inducible by injection of estradiol (SaboAttwood et al., 2004). However, the estrogen receptors (ers) have not been characterized in sand goby and it is uncertain if ers are suitable as biomarkers as their sensitivity to environmentally relevant concentrations of EED is questionable.

Our hypothesis is that sand goby possesses three er with conserved domain structures and exposure to environmentally relevant concentrations of EE2 induces time-dependent expression patterns in the hepatic expression of these er genes as well as in the multiple vtg genes already sequenced. A comparison of the temporal expression patterns of these estrogen sensitive genes will be useful for biomarker evaluation and risk assessment. The objectives are 1) to sequence multiple ers of the sand goby (at the mRNA and predicted protein level), categorize the ers by subtype and characterize the domain structures and evolutionarily conserved regions; 2) To quantify relative hepatic gene expression of ers in males EE2 exposure at environmentally relevant concentrations of EED and compare this to control females and control males; 3) characterize the temporal mRNA expression pattern of ers and vtgs throughout a long term exposure period to an EED enabling comparison of estrogen responsive genes to evaluate the sensitivity of these potential biomarkers.

\section{Materials and Methods}

\subsection{The exposure scheme}


The sand gobies used in the exposure experiments were caught using a hand trawl at natural breeding sites near the Tvärminne Zoological Station (University of Helsinki) on the southern coast of Finland. Trawling was conducted during the main breeding season (May-June). Only sexually mature fish were chosen to this study and they were separated by sex before introduction to the holding tanks. Fish were acclimated to the laboratory conditions for 2 weeks. From holding tanks fish were randomly assigned to six different exposure glass aquaria $(80 \times 80 \times 40)$. Males were kept at a density of 45 males and females were kept at a density of 15 per tank. Tanks had a $3 \mathrm{~cm}$ layer of fine sand on the bottom and were equipped with a flow-through of seawater (see Saaristo et al., 2009, 2010a,b). Fish were fed twice a day during the exposure period.

The treatment was as follows: EE2 exposure (males), with nominal concentration of $20 \mathrm{ng} / \mathrm{L}$ (measured concentration 11ng/L, standard deviation $(S D)=3.7, n=10$ ), During preparation of chemicals, EE2 (Sigma-Aldrich, Finland) powder was dissolved in acetone, which was evaporated using a stream of nitrogen thus eliminating the presence of solvent (Saaristo et al., 2010a,b). The EE2 concentration in the male exposure aquaria was measured by liquid chromatograph-mass spectrometer (LC-MS; HS 1100-Water Quattro II) using methods described in Saaristo et al., 2009). The study was approved by the Finnish National Board of Laboratory Animals.

\subsection{Cloning of estrogen receptors}

\subsubsection{Targeting unknown sand goby er sequence}

Deduced amino acid sequences for complete cDNAs of ers were sourced from the GenBank website for a variety of teleost species and aligned using CLUSTALW2 to identify conserved subtype-specific sequences (list of teleost species, protein IDs and accession numbers shown in Supplement 1). These were used to design the primers as follows: er forward primer (FP) 5' ACCACTATGGGGTGTGGTC 3' and reverse primer (RP) 5' CATGCCTTTGTTGCTCATGT 3', erb1 FP 5' GCTATGAAGTCGGCATGACC and RP 5' GATCATGGCTTTGAGGCAGA 3' and erß2 FP 5' GTGTGAGGCGTGAACGCTGC, RP 5' GCTGGCTGGAGATCCTGATG 3' for reverse transcription polymerase chain reaction (RT-PCR).

\subsubsection{RNA isolation and Reverse transcription}


Total RNA was isolated from EE2 exposed male and control female liver tissue samples $(100 \mathrm{mg})$ using NucleoSpin ${ }^{\circledR}$ RNA II kit (ABGene, Epsom, UK) following the manufacturer's protocol and quantified by Nanodrop ${ }^{\mathrm{TM}}$ ND-1000 spectrophotometer. Superscript III reverse transcriptase (Invitrogen, Paisley, UK) was used to convert $2 \mu \mathrm{g}$ RNA into cDNA, again according to the manufacturer's instructions. The reverse transcription reactions were primed using random hexamers at a reaction concentration of $1.5 \mu \mathrm{M}$ and oligodT at a reaction concentration of $3 \mu \mathrm{M}$. The reaction was incubated at $50{ }^{\circ} \mathrm{C}$ for $60 \mathrm{~min}$ and then at $70{ }^{\circ} \mathrm{C}$ for $15 \mathrm{~min}$. The $\mathrm{cDNA}$ was stored at $-20{ }^{\circ} \mathrm{C} .2 .2 .3$ PCR amplification, cloning and sequencing

RTPCR was used to amplify er fragments from livers of EE2-exposed male and control female sand goby. Reddymix ${ }^{\mathrm{TM}}$ PCR Master Mix (1.1X) (Thermo Fisher Scientific., USA) was used with 0.2 $\mu \mathrm{M}$ reaction concentration for each primer and $1 \mu \mathrm{L}$ sand goby cDNA and thermo- cycled following the manufacture's recommendations. The PCR products were analysed by agarose gel electrophoresis (data not shown) and purified fragments were cloned into pJET1.2 vector and DH5a E. coli host using the CloneJET ${ }^{\mathrm{TM}}$ PCR cloning kit (Fermentas, UK) and the Subcloning Efficiency ${ }^{\mathrm{TM}} \mathrm{DH} 5 \alpha^{\mathrm{TM}}$ Competent $^{2}$ Cells (Invitrogen, UK). Plasmids were purified from recombinant colonies (using GeneJET Plasmid Miniprep Kit, Fermentas, UK) and sequenced using GenomeLab ${ }^{\mathrm{TM}}$ Dye Terminator Cycle Sequencing with Quick Start Kit (Beckman UK) using the manufacturers' protocol on the CEQ-8000 (Beckman Coulter Inc., Fullerton, USA) and processed using Long Fast Read program 1 (LFR1), a standard setting for DNA sequencing. The sequences generated were pair aligned with er sequences from Micropogonias undulatus (era accession: AAG16713.1, er $\beta$ accession AAG16711.1 and er $\gamma$ AAG16712.1), Gambusia affinis (era accession BAF76770.1, erß1 accession: BAF76771.1 and erß2 accession: BAF76772.1), Acanthogobius flavimanus (era accession: BAF46102.1 er $\beta$ accession:BAF46103.1, Oryzias latipes (era accession BAA86925.1, er $\beta$ accession NM_001104702.1 and er $\beta 2$ accession NM_001128512.1) and Acanthopagrus schlegelii (era accession AY074780.1, accession erß AY074779.1 and erß2 accession EU346949).

\subsection{Quantification of Transcripts by Relative RT-qPCR.}

RNA extraction from sand goby liver as described in section 2.2.2. 


\subsection{2 qPCR assays}

The qPCR reactions were primed with transcript-specific primers. Primers for vtga, vtgb, vtgc and 28 S ribosomal RNA (rs28) were presented previously (Humble et al., 2013). Primers for era and erb1 were designed using Primer3 (Rozen and Skaletsky, 2000) and primer pairs were screened against potential to form secondary structures using Netprimer (Premier Biosoft 2002). The reverse transcription, quantitative, PCR (RT-qPCR) primers were validated using end-point RT-PCR to amplify cDNA from female control fish (data not shown) to demonstrate single fragments of expected size and RT-qPCR standard curves constructed to assess the efficiency for each primer set (Table 1). rs28 shows little variation in hepatic expression in different genders or response to EE2 when a fixed amount of RNA is used (CT standard deviation \pm 0.55 ) was therefore used as reference gene. All RTqPCR reactions were carried out in triplicate in 96 clear-well plates using Platinum $\AA^{8}$ SYBR $\AA$ green qPCR Supermix-UDG (Invitrogen, Paisley, UK) as previously described (Humble et al., 2013). After amplification a melting curve analysis $\left(60{ }^{\circ} \mathrm{C}\right.$ to $\left.95{ }^{\circ} \mathrm{C}\right)$ was completed for each reaction to demonstrate a single product melting at the correct temperature.

\subsection{Mathematical and statistical analysis of RTqPCR data}

The RTqPCR mathematical calculation was performed separately for each target gene. First, the mean CT values for each gene (target gene and reference gene) and each biological sample was calculated using the three technical replicates. Second, a relative expression ratio $(R)$ was generated for the gene of interest (relative to the reference gene) for each individual biological sample using the following equation presented by Pfaffl (2001) $R=\left(\left(E_{\text {target }}\right) \Delta C\right.$ Ttarget(control-sample) $) /\left(\left(E_{\text {reference }}\right){ }^{\Delta C \text { Tref(control- }}\right.$ ${ }^{\text {sample) }}$ ) with reference to assay efficiencies $(E)$ to compensate for inter-assay efficiency variation. RS28 was used as reference gene (ref) and the mean of the control samples was used as "control". Third, the $R$ values were Log10 transformed to fit approximately normal distributions as determined by Shapiro-Wilk test and show homogeneity of variance as determined by Levene's test.

Statistically significant differences in mRNA expression between control and exposed (or male and control female) samples were tested using Student's unpaired t-test. For each gene of interest, significant differences between time points were calculated using one-way ANOVA with Tukey's HSD post-hoc test. Between target gene comparisons were made using MANOVA with Tukey's HSD posthoc test. All statistical analyses were performed using the SPSS package (IBM SPSS Statistics 19). 


\section{Results}

\subsection{Partial sequencing of two estrogen receptors in sand goby}

RTPCR products of anticipated size were produced for a putative era and erß1 from EE2exposed male and control female sand goby liver, but no product for er $\beta 2$ was formed even after using alternative tissues and primers (data not shown). The PCR products were cloned and sequenced resulting in contigs $977 \mathrm{bp}(e r \alpha)$ and $600 \mathrm{bp}$ (erß1) in length that were used as queries for BLASTx search and showed highest homology to era (accession: BAF46102.1, E-value: $8 e^{-121}$ ) and erß (accession: BAF46103.1, E-value: $7 \mathrm{e}^{-120}$ ) of Japanese common goby (Acanthogobius flavimanus). The er $\beta$ of the Japanese common goby has not been categorized as subtype er $\beta 1$ or er $\beta 2$ yet the sand goby cDNA fragment has high similarity with erß1 of other species (such as estrogen receptor beta1, partial [Acanthopagrus latus] accession: gb|AEX68678.1) to suggest this novel sand goby fragment is subtype erß1.

To confirm the identity of the cDNA fragments, the sequences were translated, to generate 325 aa for era and 200 aa for erß1, and pair-aligned using water alignment with full length protein sequences of ers from other teleosts species (Micropogonias undulatus, Gambusia affinis, Acanthogobius flavimanus, Oryzias latipes and Acanthopagrus schlegelii). Sand goby era (accession: KC782769) showed highest identity with Japanese common goby era (90.2\%) while sand goby er $\beta 1$ (accession: KC782770) shows greatest homology with er $\beta$ of the Japanese common goby (89.4\%). The partial sand goby era and erß1 deduced protein sequences pair-alignments with full length Japanese common goby era and er $\beta$ protein sequence are shown in Fig. 1A and Fig. 1B respectively.

For era, the sand goby sequence covers 60 amino acids (aa) of the 76 aa-long DNA binding domain, all the hinge domain and 201 aa of the 238 aa ligand-binding domain. There was a $100 \%$ match for the DNA binding domain, a $61.5 \%$ match for the hinge domain and a $93.9 \%$ match for the ligand binding domain. For erB1 the sand goby sequence covered 15 aa of the 79 aa-long DNA binding domain, (93.3\% match), all of the 41 aa hinge domain, (65.9\%), and covered 143 of the 238 aa-long ligand binding domain (95.8\%).

\subsection{EE2 induced male er gene expression compared with female}


Primers (shown in Table 1) were designed for RT-qPCR to amplify fragments of $158 \mathrm{bp}$ long for both sand goby era and er $\beta 1$. The endogenous mRNA levels of er and er $\beta 1$ in male and female sand goby were analyzed using RT-qPCR. Very low mRNA levels were found for both ers in control males (mean CT for era was 26.7 and for erb1 was 25.2). Females had higher endogenous levels of era (mean CT: 20.02) than erß1 (mean CT: 26.2).

Relative RT-qPCR was used to analyse the fold change in era mRNA in male sand goby exposed to $11 \mathrm{ng} / \mathrm{L}$ EE2 for 29 days to show a highly significant increase in era mRNA. A significant difference in era was found between control males and females but no significant difference was found between females and EE2 exposed males indicating this exposure induced hepatic era expression in males similar to that of females. A small but significant difference in er $\beta 1$ was found between control males and males exposed to EE2 but no significant difference was found comparing control males with females.

\subsection{Vtg-a, -b, -c \& era expression over a month-long exposure to EE2}

Relative RT-qPCR was used to analyse vtga, vtgb, vtgc and era mRNA levels in control and EE2-exposed (11 ng/L) male sand goby liver at 6 time points throughout 29 days (Fig. 3). Unexposed males had very low levels of mRNA for era and all vtg subtypes throughout the 29 day exposure period. This was detectable by highly significantly, lower $\mathrm{C}_{\mathrm{T}}$ values compared with non-template control (NTC). For instance, the mean CT values for the unexposed males at day 29 were 26.7, 29.4, 29.9 and 26.7 for vtga, vtgb, vtgc and era respectively while the respective NTC values were undetermined, $35.1,36.4,38.2$ and 37.9 for the respective genes.

Samples from exposed males had a highly significant $(p<0.0001)$ increase in levels of $v t g-a-b$ and $-c$ mRNA expression compared with controls at all time-points measured. On the other hand, era showed significant differences $(p<0.05)$ at day 13 and 16 , very significant differences at day 8,24 and $29(p<0.01)$ but no significant difference at day 20 when comparing exposed and control samples.

Expression of mRNA in males exposed to $11 \mathrm{ng} / \mathrm{L}$ over 29 days EE2 relative to controls was used for comparison of multiple time-points to show increases in expression ratios for $v \operatorname{tg}-a,-b,-c$ and era 
and reveal distinct temporal and transcript specific changes in mRNA upregulation. For vtga, there was a sharp rise at the beginning of the time course shown by a statistically significant increase between day 8 and all other time points. Day 29 was also significantly greater than day 8, 13, 16 and 24 showing that vtga continued to rise at the later stages. Vtgb on the other hand showed no significant difference between day 8 and day 13,16 or 20 but here was a difference between day 8 and day 24 or 29 . Vtgb expression reached a plateau indicated by a lack of statistically significant differences between day 16, 20, 24 and 29. For vtgc, day 8 was found to be significantly different from all other time points measured. Day 29 was found to be significantly higher than day 8,13 and 16 , but not significantly different to day 20 or 24 . For era there was a significant difference between day 29 and days 8,13 or 20 however there was no significant difference comparing day 13 or day 20 with any other time point.

A comparison was also carried out between relative mRNA expression levels of $v t g$ target genes over the time course. At day 8 of exposure the relative expression levels of the vtgs was in the order $v \operatorname{tg} a>v \operatorname{tg} c>v \operatorname{tg} b$ (ratio of relative gene expression $v \operatorname{tga}: v \operatorname{tgc}:$ tgb, for exposed male $1.53: 1.13$ : 1) though this was found not to be significantly different. However at day 29 there was a significant difference (with $v \operatorname{tg} a>v \operatorname{tg} c>v \operatorname{tg} b$ ) and the respective abundance ratio for vtga : vtgc: $v \operatorname{tg} b$ was 6.94 : $2.34: 1$ indicating a divergence in the expression profiles for these three genes over time.

\section{Discussion}

\subsection{Analysis of novel er $\alpha$ and er $\beta 1$ sequences}

We successfully cloned and sequenced two cDNA fragments from liver of sand goby which show high homology to era and er $\beta 1$ in other fish species. These sequences were translated to gain partial deduced protein sequences which were aligned with Japanese common goby (Acanthogobius flavimanus) deduced proteins to show they had higher similarity at the DNA binding domains and ligand domains than the hinge domains. This is consistent with the functional roles of these domains reportedly conserved during evolution (Aranda and Pascual, 2001). Ray-finned fish (Actinopteriygii) contain multiple ers due to gene and genome duplication. Typically there are three er genes in teleosts as described in the Atlantic croaker (Micropogonias undulates) and largemouth bass 
218 (Micropterus salmoides) (Hawkins et al., 2000; Sabo-Attwood et al., 2004). It is possible that our

219 efforts to clone er $\beta 2$ failed for technical reasons but it is of interest that only two ers $(\alpha$ and $\beta)$ are 220 found in the closely related Japanese common goby (Ito et al., 2007). Phylogenetic analysis suggests that $\operatorname{er} \beta 1$ and $\operatorname{er} \beta 2$ are the result of duplication in an ancestor that was shared with higher vertebrates in which only a single erß is present (Nelson and Habibi, 2013). It is unlikely that the goby lineage were not subject to the same duplication event considering erß of mammals shares more identities with erß2 of fish than with erß1 (Hawkins and Thomas, 2004). It is more likely that erß2 was redundant and was lost in the goby lineage and all er $\beta$ functions are maintained by er $\beta 1$. Phylogenetic analysis of VTGs also suggests a distinct evolutionary pathway in the gobies compared to other rayfinned fish (Thacker, 2009).

228

\subsection{Expression of estrogen receptor genes}

Our study shows that the sand goby has gender-specific patterns of hepatic er expression and by comparison, transcript levels of both ers were low in male with erß1 marginally higher than that of era. In contrast ers are reported as absent from the liver of male Japanese common goby but this may be the consequence of an insensitive end-point PCR technique used in that investigation (Ito et al., 2007). Work on zebrafish (Danio rerio) has indicated that endogenous levels of er $\beta 1$ are higher than that of era or erß2 (Menuet et al., 2004) but it was unclear which gender of fish were used in that study. Meng et al., (2010) reported gender differences in er transcript levels in zebrafish liver with era and $\operatorname{er} \beta 2$ in females being at higher levels than er $\beta 1$ while in males er $\beta 1$ and era were observed at very low levels and erß2 was higher. The results reported here indicate that sand goby is similar to zebrafish in respect of gender differences in hepatic expression of era and erß1 but differ because in sand goby, no erß2 has been found.

In this study we demonstrated a marked increase in transcripts for era, up to levels comparable to those seen in mature females, and a modest increase in er $\beta 1$ in response to EE2 exposure. Exposure of male Japanese common goby to xeno-estrogens has been reported to result in the induced hepatic expression of estrogen-dependent genes implying the presence of ers (Ohkubo et al., 2004). Here, temporal variation in transcription for era in male liver was studied over a 29 day EE2 exposure, and a very significant increase in era relative to the control group was seen at day 24 and expression continued to rise at day 29. This observation promotes the idea that er may be a suitable biomarker 
247 for EED exposure-monitoring in male sand goby with high mRNA levels in particular signaling 248 prolonged EED exposure. In zebrafish short term exposure (48 hours) to 17ß-oestradiol has been 249 reported to cause disparate effects upon the hepatic transcript levels of the er, with era increasing erß1 decreasing (Menuet et al., 2002), which suggests zebrafish is dissimilar to sand goby regarding

251

252

253

254

255

256

257

258

259

260

261

262

263

264

265

266

267

268

269

270

271

272

273

274

275 its downregulation of er $\beta 1$ in response to estrogens. The results reported here show similarity with those reported in largemouth bass where the three er subtypes are classified as $\alpha, \beta$ (er $\beta 2$ ) and $y$ (er $\beta 1$ ). Sand goby $\beta 1$ showed greatest similarity to largemouth bass $\gamma$ type. Similar to the sand goby, the liver of largemouth bass females has higher endogenous levels of era than ery, and the injection of males with E2 causes a large increase in era and a moderate increase in ery (Sabo-Attwood et al., 2004). The increase in era expression found in EED exposed sand goby may act as a positive feedback, compounding the feminization process and further sensitizing the males to estrogen exposure. Here we have for the first time in a teleost species demonstrated the induction of era and erB1 by exposure to environmentally relevant concentrations of EED.

\subsection{Expression of vitellogenin genes}

The determination of complete sequences for three VTGs (accessions: JQ511252.1, JQ511253.1 and JQ511254.1) and the development of vtg type specific RT-qPCR assays (Humble et al., 2013) opened the door for a study of the temporal effects of EE2 on the abundance of these transcripts. Low levels of transcripts for all of the vtg types were found in liver of non-exposed males, arguably the result of low level exposure to an estrogenic chemical during the maintenance and treatment periods. We can discount that these low vtg levels in males were caused by EE2 since in control tanks EE2 was below detection level by LC-MS-MS quantification (Saaristo et al., 2010a). Other researchers have also found basal level of VTG mRNA in untreated males in Murray rainbowfish (Melanotonia fluviatilis) (Woods and Kumar, 2011) Japanese medaka (Oryzias latipes) (Sun et al., 2011) and zebrafish (Söffker et al., 2012). Endogenous male estrogen synthesis is essential for testicular development and sperm formation in vertebrates including fish (Schulz et al., 2010) thus could be responsible for basal vtg mRNA expression. However, other factors such as hypoxia and parasite infection are also known to stimulate vitellogenin expression in males (Murphy et al., 2009).

Exposure of male sand goby to EE2 $(11 \mathrm{ng} / \mathrm{L})$ resulted in large increases of each vtg type with $v \operatorname{tg} a>v \operatorname{tg} c>v \operatorname{tg} b$ at all-time points although the differences in gene expression were only found to be 
significant at day 29. Considering a significant difference between the relative levels of $v \operatorname{tga}, v \operatorname{tg} b$ and vtgc was only found at later time-points of the EE2 exposure, statistical comparison of the hepatic expression of these vtg genes may be used as an indicator for the duration of estrogen contamination of coastal environments prior to sampling thus providing information useful to risk assessment in marine ecotoxicology.

At early time-points the level of each transcript was similar to that seen in vitellogenic females (Humble et al., 2013). In many other fish species induction of vtg mRNA and protein is observed with LOECs for EE2 in the range $5-10 \mathrm{ng} / \mathrm{L}$ suggesting that the sand goby is as sensitive to estrogenic endocrine disruption as the other species investigated (Woods and Kumar, (2011)). However, clear temporal differences between vtg types became apparent after 20 days of exposure with vtgb reaching a plateau while the rate of increase for vtgc slowed and vtga continued to increase. It is notable that the continued increase in vtga occurs at the same time that era increases markedly. This makes it plausible that the EED-induced temporal rise of era promotes a continued increase in vtg expression. Future work will test this hypothesis by cloning the promoter regions of vtg genes and studying their era-dependent control of transcription.

Future work will also apply these assays to study the natural seasonal variation in the production of multiple vtgs in females and the effects that EEDs on vitellogenesis. It is conceivable that the normal pattern of $v t g$ production in females is altered by such exposure and that this may not produce an optimum balance of nutrient for embryonic development.

\subsection{Conclusions}

Unlike the situation in many other teleosts only two ers are evident in the sand goby. Both can be induced in males by EE2 exposure, a consequence of which might be to exacerbate the adverse effects of EED exposure. Supporting evidence is provided by the observation that the temporal increase in er expression occurs coincidentally with an increase in expression of $v \operatorname{tga}, \operatorname{vtg} b$ and $v \operatorname{tgc}$ with vtga demonstrating the greatest temporal and total increase. The temporal change in era and vtgs transcript abundance reveals variation in the sensitivity of each of these potential biomarkers which is helpful for assessing their potential as biomarkers. The significant difference between the 


\section{Acknowledgement.}

JLH thanks the Natural Environment Research Council (UK) for a Doctoral Training Grant

(NE/G523398/1). MS, KL and KKL thank the Onni Talas Foundation (Finland) for funding.

\section{References}

Aranda, A., Pascual, A., 2001. Nuclear hormone receptors and gene expression. Physiol. Rev. 81, 1269-304.

Hawkins, M.B., Thomas, P., 2004. The unusual binding properties of the third distinct teleost estrogen receptor subtype ERbetaa are accompanied by highly conserved amino acid changes in the ligand binding domain. Endocrinology 145, 2968-77.

Hawkins, M.B., Thornton, J.W., Crews, D., Skipper, J.K., Dotte, a, Thomas, P., 2000. Identification of a third distinct estrogen receptor and reclassification of estrogen receptors in teleosts. Proc. Natl. Acad. Sci. U. S. A. 97, 10751-6.

Healey, M.C., 1971. The distribution and abundance of sand gobies, Gobius minutus, in the Ythan estuary. J. Zool. 163, 177-228.

Hiramatsu, N., Cheek, A.O., Sullivan, C. V, Matsubara, T., Hara, A., 2005. Chapter 16 Vitellogenesis and endocrine disruption, in: Biochemistry and Molecular Biology of Fishes. Elsevier, pp. 431471.

Humble, J.L., Hands, E., Saaristo, M., Lindström, K., Lehtonen, K.K., Diaz, O., Cerio, D., Cancio, I., Wilson, G., Craft, J.A., 2013. Characterisation of genes transcriptionally upregulated in the liver of sand goby (Pomatoschistus minutus) by 17 alpha-ethinyloestradiol : Identification of distinct vitellogenin and zona radiata protein transcripts. Chemosphere 90, 2722-2729.

Ito, K., Mochida, K., Fujii, K., 2007. Molecular cloning of two estrogen receptors expressed in the testis of the Japanese common goby, Acanthogobius flavimanus. Zoolog. Sci. 24, 986-996.

Katsiadaki, I., Scott, A.P., Hurst, M.R., Matthiessen, P., Mayer, I., 2002. Detection of environmental androgens: a novel method based on enzyme-linked immunosorbent assay of spiggin, the stickleback (Gasterosteus aculeatus) glue protein. Environ. Toxicol. Chem. 21, 1946-54.

Kirby, M.F., Bignell, J., Brown, E., Craft, J.A., Davies, I., Dyer, R.A., Feist, S.W., Jones, G., Matthiessen, P., Megginson, C., Robertson, F.E., Robinson, C., 2003. The presence of morphologically intermediate papilla syndrome in United Kingdom populations of sand goby (Pomatoschistus spp.): Endocrine disruption? Environ. Toxicol. Chem. 22, 239-251.

Meng, X., Bartholomew, C., Craft, J.A., 2010. Differential expression of vitellogenin and oestrogen receptor genes in the liver of zebrafish, Danio rerio. Anal. Bioanal. Chem. 396, 625-630. 
Menuet, A., Le Page, Y., Torres, O., Kern, L., Kah, O., Pakdel, F., 2004. Analysis of the estrogen regulation of the zebrafish estrogen receptor (ER) reveals distinct effects of ERalpha, ERbeta1 and ERbeta2. J. Mol. Endocrinol. 32, 975-86.

Menuet, A., Pellegrini, E., Anglade, I., Blaise, O., Laudet, V., Kah, O., Pakdel, F., 2002. Molecular characterization of three estrogen receptor forms in zebrafish: binding characteristics, transactivation properties, and tissue distributions. Biol. Reprod. 66, 1881-92.

Murphy, C.A., Rose, K.A., Rahman, M.S., Thomas, P., 2009. Testing and applying a fish vitellogenesis model to evaluate laboratory and field biomarkers of endocrine disruption in Atlantic croaker (Micropogonias undulatus) exposed to hypoxia. Environ. Toxicol. Chem. 28, 1288-1303.

Nelson, E.R., Habibi, H.R., 2013. Estrogen receptor function and regulation in fish and other vertebrates. Gen. Comp. Endocrinol. 192, 15-24.

Ohkubo, N., Andoh, T., Mochida, K., Adachi, S., Hara, A., Matsubara, T., 2004. Deduced primary structure of two forms of vitellogenin in Japanese common goby (Acanthogobius flavimanus). Gen. Comp. Endocrinol. 137, 19-28.

Pojana, G., Bonfà, A., Busetti, F., Collarin, A., Marcomini, A., 2004. Estrogenic potential of the Venice, Italy, lagoon waters. Environ. Toxicol. Chem. 23, 1874-1880.

Robinson, C.D., Brown, E., Craft, J.A., Davies, I.M., Moffat, C.F., Pirie, D., Robertson, F., Stagg, R.M., Struthers, S., 2003. Effects of sewage effluent and ethynyl oestradiol upon molecular markers of oestrogenic exposure, maturation and reproductive success in the sand goby (Pomatoschistus minutus, Pallas). Aquat. Toxicol. 62, 119-134.

Rozen, S., Skaletsky, H., 2000. Primer3 on the WWW for general users and for biologist programmers. Methods Mol. Biol.

Saaristo, M., Craft, J.A., Lehtonen, K.K., Lindström, K., 2009. Sand goby (Pomatoschistus minutus) males exposed to an endocrine disrupting chemical fail in nest and mate competition. Horm. Behav. 56, 315-321.

Saaristo, M., Craft, J.A., Lehtonen, K.K., Lindström, K., 2010a. Exposure to 17a-ethinyl estradiol impairs courtship and aggressive behaviour of male sand gobies (Pomatoschistus minutus). Chemosphere 79, 541-546.

Saaristo, M., Craft, J.A., Lehtonen, K.K., Lindström, K., 2010b. An endocrine disrupting chemical changes courtship and parental care in the sand goby. Aquat. Toxicol. 97, 285-292.

Sabo-Attwood, T., Kroll, K.J., Denslow, N.D., 2004. Differential expression of largemouth bass (Micropterus salmoides) estrogen receptor isotypes alpha, beta, and gamma by estradiol. Mol. Cell. Endocrinol. 218, 107-18.

Schulz, R.W., de França, L.R., Lareyre, J.-J., Le Gac, F., LeGac, F., Chiarini-Garcia, H., Nobrega, R.H., Miura, T., 2010. Spermatogenesis in fish. Gen. Comp. Endocrinol. 165, 390-411.

Söffker, M., Stevens, J.R., Tyler, C.R., 2012. Comparative Breeding and Behavioral Responses to Ethinylestradiol Exposure in Wild and Laboratory Maintained Zebrafish (Danio rerio) Populations. Environ. Sci. Technol. 46, 11377-11383.

Sun, L., Shao, X., Wu, Y., Li, J., Zhou, Q., Lin, B., Bao, S., Fu, Z., 2011. Ontogenetic expression and $17 \beta$-estradiol regulation of immune-related genes in early life stages of Japanese medaka (Oryzias latipes). Fish Shellfish Immunol. 30, 1131-7. 
Thacker, C., 2009. Phylogeny of Gobioidei and Placement within Acanthomorpha, with a New Classification and Investigation of Diversification and Character Evolution. Copeia 2009, 93-104.

Woods, M., Kumar, A., 2011. Vitellogenin induction by $17 \beta$-estradiol and $17 \alpha$-ethynylestradiol in male Murray rainbowfish (Melanotaenia fluviatilis). Environ. Toxicol. Chem. 30, 2620-7.

\section{Legends to Figures}

Fig.1. Alignment of sand goby partial protein sequences with full length protein sequences of Japanese goby era (A) and erß1 (B) by ClustalW2. Green text represents the N-terminal domain, red text the DNA binding domain, yellow text the hinge domain and blue text the ligand binding domain. Numbers represent the amino acid residues, $-=$ gap, ${ }^{*}=$ fully conserved residue, $:=$ strongly similar residue.$=$ weakly similar residue .

Fig. 2. Hepatic er a and erß1 relative mRNA expression in livers of control female and EE2treated male sand goby relative to control males determined by relative RTqPCR. EE2 treated males were exposed to EE2 at $11 \mathrm{ng} / \mathrm{L}$ for 29 days. Numbers of individuals are as follows: control males $n=$ 7, exposed males $n=7$ and control females $n=8$. Error bars represent standard error for the mean (SEM) and statistical signicance between control males and control females or exposed males were determined by Student's unpaired t-test test ${ }^{* *}=\mathrm{P}<0.01^{* * *}=\mathrm{P}<0.001$.

Fig. 3. Temporal, hepatic vtga, vtgb, vtgc and era relative mRNA expression in EE2 exposed (11 $\mathrm{ng} / \mathrm{L}$ ) (solid line) and control (dashed line) male sand goby. Data represent mean expression values \pm SEM normalized using RS28 reference gene and relative to control fish sampled at each time point. Unpaired student t-test was used to test for significant difference between exposed and control samples $\left({ }^{*}=p<0.05 ;{ }^{* *}=p<0.01 ;{ }^{* *}=p<0.001\right)$. Separately for each gene of interest, one-way ANOVA with Tukey HSD post-hoc test was used to test for significant differences between time points in exposed samples, The same letter $(a, b, c)$ indicate no significant difference between time points whereas different letters indicate significant differences $(p<0.05)$ between time points. 
A)
MYPEESRGSGGVATVDFLDGTYDYTAPTPAPTLYSHSSTGYFSAPLDVHGPPSDGSLQSL 60 GSGPNSPLMFVPSSPHLSPFMHPPSHHYLETSSTPIYRSGVPSTQQLSREEHNGAEEAFR 120 ERo_A._flavimanus ERQ_P._minutus $E R \alpha \_$_._flavimanus ERQ_P._minutus

$\mathrm{ER} \alpha \_$A._flavimanus ERQ_P._minutus

ERQ_A._flavimanus ERQ_P._minutus

ERo_A._flavimanus ERo_P._minutus

ERo_A._flavimanus ERQ_P. minutus

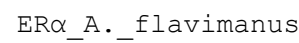
ERo_P._minutus

ER $\alpha$ A._flavimanus $\mathrm{ER} \alpha \_\mathrm{P} \cdot$ _minutus

\section{$E R \alpha \_A . \_f l a v i m a n u s$} ERQ_P._minutus

\section{VSESGSGTGVGPGGFEMAKETRE}

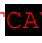

KAFFKRSIQGHNDY
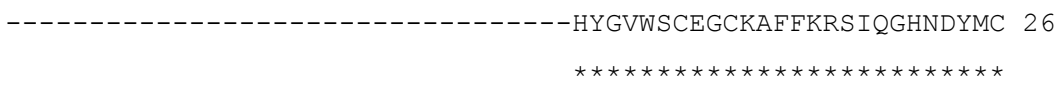

RLRKCYEVGMMKGGIRKDRGRVLRRDKRRTDRDKSSKDSCQ 240 PATNQCTIDRNRRKSCQACRLRKCYEVGMMKGGIRKDRGRVVRRDKRKPDKDKNSKGSHP 86

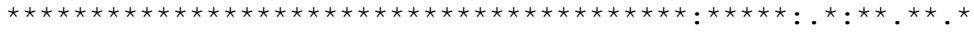

KTAPPQDNKKHYSSNAGGGAKFAVSGMSPDQVLQLLQGAEPPILCSRQKLNGPYTEGTMM 300 KTAPLQD-KRQYVSSSGGQAKLSITGMSPDQVLQLLQGAEPPILCSRQKLSGPYTEITMM 145

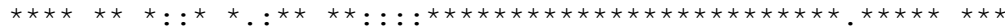

SLLTSMADKELVHMIAWAKKLPGFLQLSLHDQVLLLESSWLEVLMISLIWRS IHCPGKLI 360 TLLTSMADKELVHMIAWAKKLPGFLQLSLHDQVLLLESSWLEVLMISLIWRS IHCPGKLI 205

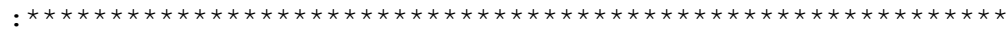

FARDLILDRDEGECVEGMAEIFDMLLATASRFRMLKLRPEEFICLKAIILPNSGAFSFCT 420 FAQDLILDRSEGDCVEGMAEIFDMLLATASRFRMLKLRPEEFICLKAIILLNSGAFSFCT 265

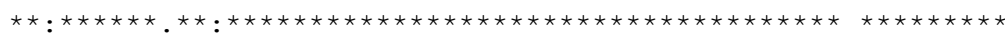

GTMEPLHDSAAVQNILDTITDALIHHISQSGYSAQQQSRRQAQLLLLLSHIRHMSNKGME 480 GTMEPLHDAAAVQSILDTITDALIYHISQSGYSGQQQARRQAQLLLLLSHIRHMSNKGMI 325 HLYNMKCKNKVPLYDLLLEMLDAHHLHHPVRTNQASSLNNSDPVYGSSSSLSSDPRGTST 540

GGGKMSSPSVLQFGGSPGNCTHIA 564 
B)

KAFFKRSIQGHNDYICPATNQCTIDKNRRKSCQACRLRKCYEVGMTKCGMRKERGTLRSP 240 


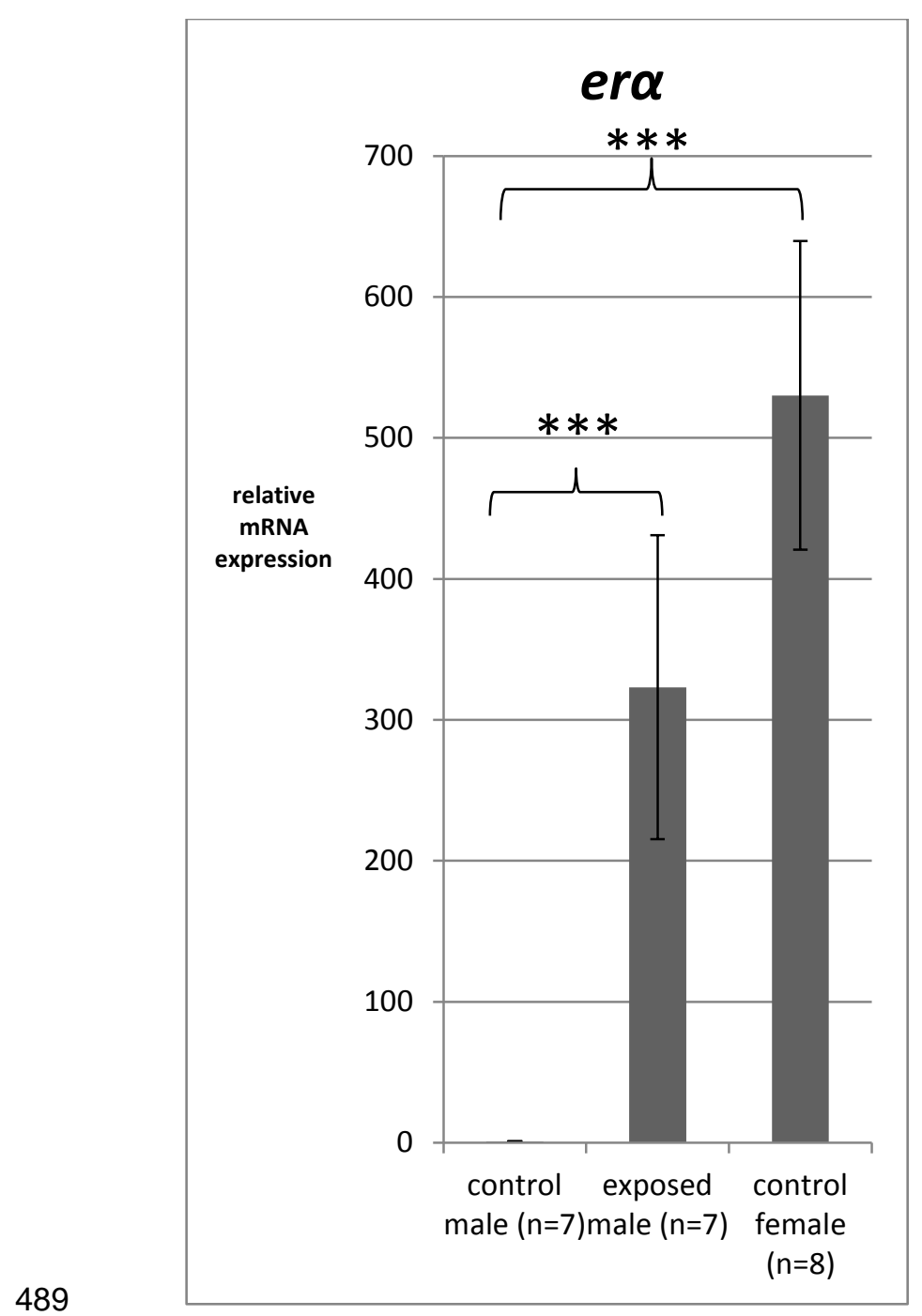




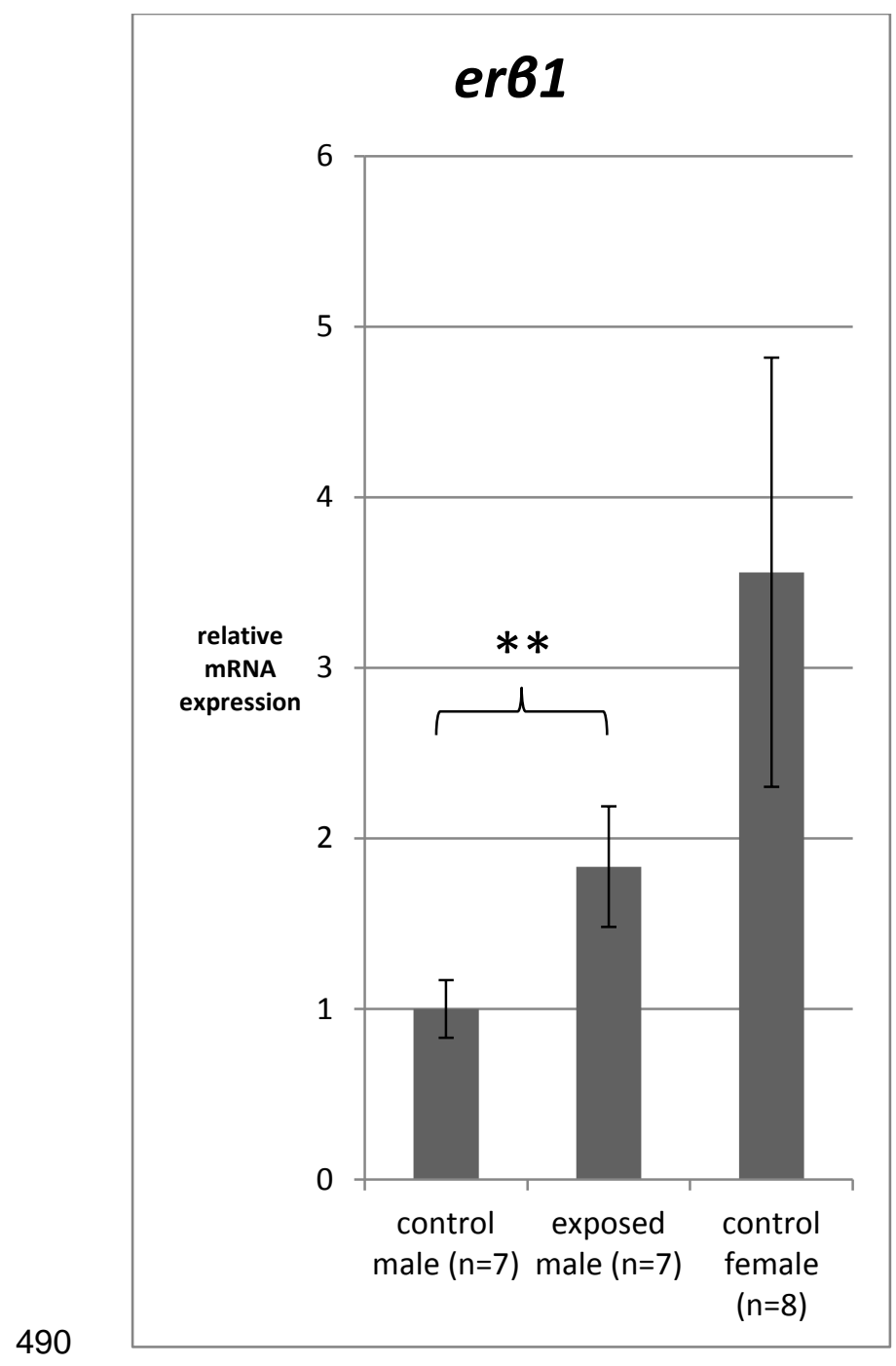

491

Fig 2

492 
vtga

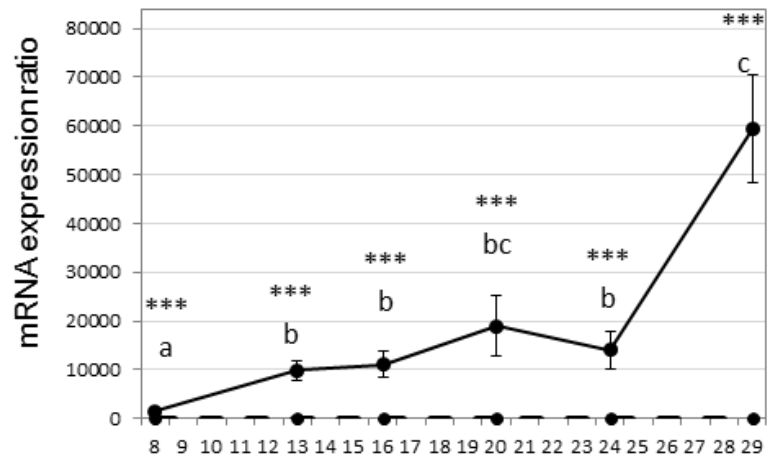

vtgc

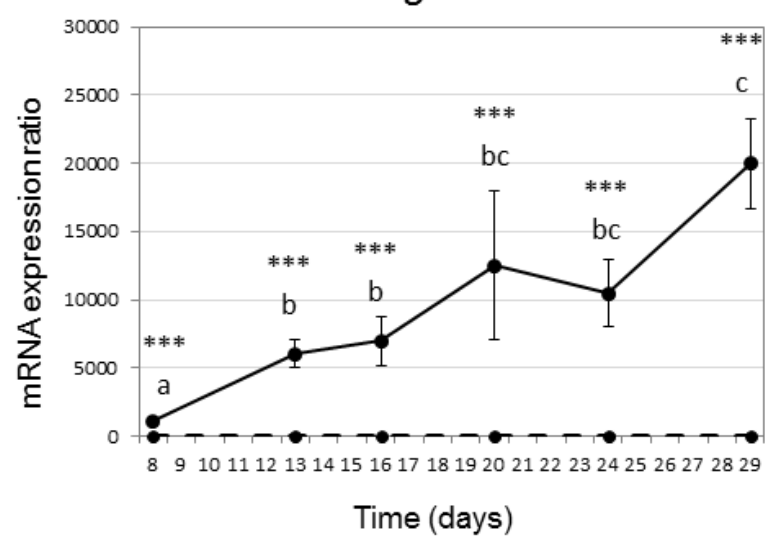

vtgb

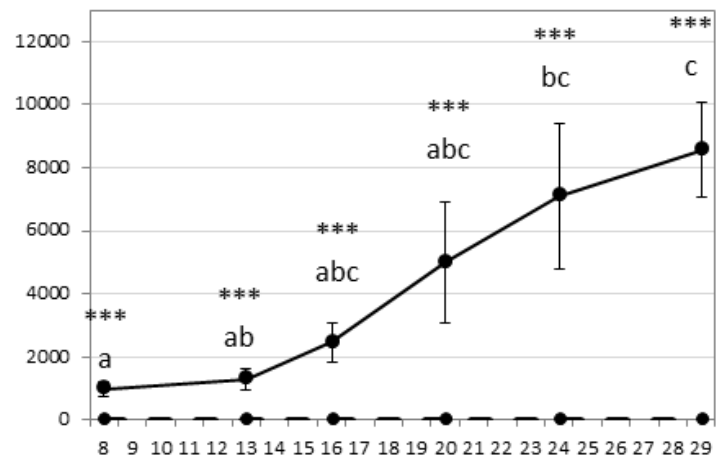

era

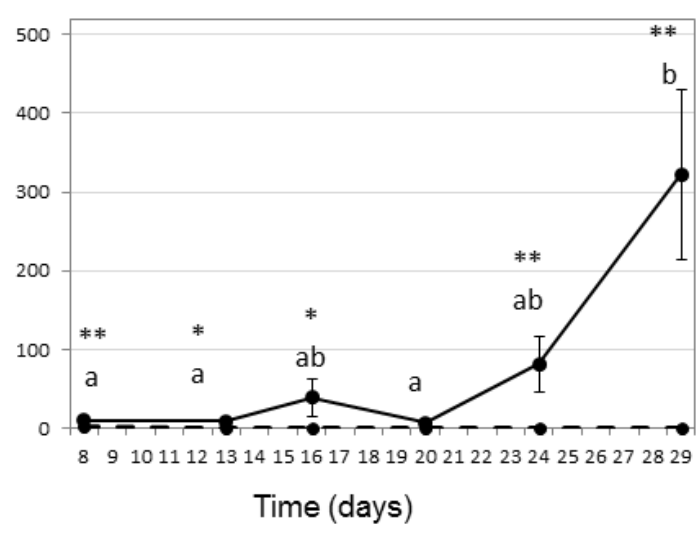

495

496 